\title{
and \\ Current Trends in Endoscopic Diagnosis and Treatment of Early Esophageal Cancer
}

\author{
Franz Ludwig Dumoulin ${ }^{1, *}$, Ralf Hildenbrand ${ }^{2}$, Tsuneo Oyama ${ }^{3}$ and Ingo Steinbrück ${ }^{4}$ \\ 1 Department of Medicine and Gastroenterology, Gemeinschaftskrankenhaus Bonn, \\ Academic Teaching Hospital, University of Bonn, D-53113 Bonn, Germany \\ 2 Institute for Pathology Bonn-Duisdorf, D-53123 Bonn, Germany; hildenbrand@patho-bonn.de \\ 3 Department of Endoscopy, Saku Central Hospital Advanced Care Center, Saku, 3400-28 Nakagomie, Nagano, \\ Japan; oyama@coral.ocn.ne.jp \\ 4 Department of Medicine, Evangelisches Diakoniekrankenhaus Freiburg, Academic Teaching Hospital, \\ University of Freiburg, D-79110 Freiburg, Germany; ingo.steinbrueck@diak-fr.de \\ * Correspondence: f.dumoulin@gk-bonn.de; Tel.: +49-228-508-1561
}

Citation: Dumoulin, F.L.; Hildenbrand, R.; Oyama, T.; Steinbrück, I. Current Trends in Endoscopic Diagnosis and Treatment of Early Esophageal Cancer. Cancers 2021, 13, 752. https://doi.org/ 10.3390/cancers 13040752

Academic Editor:

Ulrich Ronellenfitsch

Received: 30 December 2020

Accepted: 8 February 2021

Published: 11 February 2021

Publisher's Note: MDPI stays neutral with regard to jurisdictional claims in published maps and institutional affiliations.

Copyright: (c) 2021 by the authors. Licensee MDPI, Basel, Switzerland. This article is an open access article distributed under the terms and conditions of the Creative Commons Attribution (CC BY) license (https:// creativecommons.org/licenses/by/ $4.0 /)$.
Simple Summary: Early esophageal cancer is diagnosed in the context of reflux disease, surveillance of Barrett's metaplasia, or during upper gastrointestinal endoscopy for other indications. High definition and virtual or dye chromoendoscopy are mandatory for the screening and evaluation of neoplasia. Endoscopic treatment options include endoscopic mucosal resection (EMR) or endoscopic submucosal dissection (ESD). Resection is considered curative if histopathology confirms low or absent risk of lymph node metastasis. Barrett's high-grade dysplasia or early adenocarcinoma is treated by EMR or ESD, followed by ablation of Barrett's epithelium to avoid metachronous cancer. ESD is the treatment of choice for squamous cell neoplasia. Excellent outcomes have been reported if the ESD of squamous cell cancer with slight submucosal infiltration and thus substantial risk for lymph node metastasis was combined with adjuvant chemo-radiotherapy. In contrast, infiltration of squamous cell cancer exceeding the lamina propria mucosae is not curative. However, despite a substantial risk of lymph node metastasis, excellent outcomes have recently been reported if endoscopic resection of tumors with up to $200 \mu \mathrm{m}$ submucosal infiltration was combined with adjuvant chemo-radiotherapy.

Abstract: Diagnosis of esophageal adenocarcinoma mostly occurs in the context of reflux disease or surveillance of Barrett's metaplasia. Optimal detection rates are obtained with high definition and virtual or dye chromoendoscopy. Smaller lesions can be treated with endoscopic mucosal resection. Endoscopic submucosal dissection (ESD) is an option for larger lesions. Endoscopic resection is considered curative (i.e., without significant risk of lymph node metastasis) if histopathology confirms en bloc and R0 resection of a well-differentiated (G1/2) tumor without infiltration of lymphatic or blood vessels and the maximal submucosal infiltration depth is $500 \mu \mathrm{m}$. Ablation of remaining Barrett's metaplasia is important, to reduce the risk of metachronous cancer. Esophageal squamous cell cancer is associated with different risk factors, and most of the detected lesions are diagnosed during upper gastrointestinal endoscopy for other indications. Virtual high definition and dye chromoendoscopy with Lugol's solution are used for screening and evaluation. ESD is the preferred resection technique. The criteria for curative resection are similar to Barrett's cancer, but the maximum infiltration depth must not exceed lamina propria mucosae. Although a submucosal infiltration depth of up to $200 \mu \mathrm{m}$ carries a substantial risk of lymph node metastasis, ESD combined with adjuvant chemo-radiotherapy gives excellent results. The complication rates of endoscopic resection are low, and the functional outcomes are favorable compared to surgery.

Keywords: squamous cell esophageal cancer; gastro-esophageal reflux disease; Barrett's esophagus; early adenocarcinoma of esophagus; endoscopic submucosal dissection; endoscopic mucosal resection 


\section{Introduction}

According to a recent update from the Globoscan database, esophageal cancer is the seventh most prevalent cancer and the sixth most common cause of cancer-related mortality worldwide [1]. Over $90 \%$ of esophageal cancers are due to subtypes of squamous cell cancer or adenocarcinoma. Cancer-related mortality correlates with tumor stage at diagnosis with an overall five year survival rate of less than $20 \%$ [2]. While squamous cell cancer is the most prevalent subtype worldwide, dominant in Asia and Africa, there is an increasing prevalence of adenocarcinoma in high-income countries where this subtype today is more prevalent than squamous cell cancer [1,3-5]. This difference is thought to reflect the different distribution of risk factors, i.e., smoking, alcohol consumption, and environmental factors associated with squamous cell cancer versus obesity, gastro-esophageal reflux disease, and Barrett's metaplasia as risk factors for adenocarcinoma. With the advent of high-definition endoscopy and the development of advanced endoscopic resection and ablation techniques, the concept of organ-preserving treatment for early esophageal cancer has been established with excellent survival rates and minimal associated morbidity. This review focuses on the latest trends in the endoscopic diagnosis and treatment of early esophageal neoplasia.

\section{Barrett's Esophagus, High-Grade Dysplasia, and Early Adenocarcinoma}

\subsection{Screening for the Presence of Barrett's Esophagus}

The incidences of gastro-esophageal reflux disease, Barrett's esophagus, and esophageal adenocarcinoma are increasing in Western countries. Thus, screening for Barrett's esophagus and surveillance for possible progression to high-grade dysplasia and (early) esophageal adenocarcinoma, including the option of endoscopic treatment, is a desirable concept. However, to date, there is no recommendation for population-based endoscopic screening. Instead, most guidelines suggest selected screening for long standing gastro-esophageal reflux disease with additional risk factors, such as age $>50$ years, male gender, Caucasian ethnicity, obesity, or family history of Barrett's esophagus or adenocarcinoma [6-9]. A recent evaluation of these guidelines demonstrated poor test characteristics with either low or absent specificity leading to unnecessary endoscopies or unacceptably low sensitivity [10]. To overcome these problems, new technologies are being evaluated. Thus, promising data have been demonstrated for a non-endoscopic cytosponge test to detect the expression of the metaplasia biomarker trefoil factor 3 . The method involves swallowing an encapsulated brush attached to a string. The capsule then dissolves in the stomach, and the expanded sponge is withdrawn to obtain the brush cytology [11]. Moreover, a breath test using an artificial intelligence supported sensor system to evaluate patterns of volatile organic compounds was shown to predict the presence of Barrett's esophagus with high sensitivity and specificity [12]. Yet, with current guideline recommendations and pending further optimization of alternative non-endoscopic tests, the detection of Barrett's esophagus still occurs most often in the setting of upper endoscopy performed for other indications than dedicated screening [5]. It is very unfortunate that a recent retrospective study on 123,395 upper gastrointestinal endoscopies calculated a miss rate for esophageal cancer of $6.5 \%$ with an associated two year survival rate of only $20 \%$ [13]. Thus, it seems to be more than justified to define a neoplasia detection rate as a quality indicator for upper endoscopy in patients with reflux disease [14].

\subsection{Detection and Evaluation of High-Grade Dysplasia and Early Adenocarcinoma}

Considerable efforts have been made to optimize the detection of dysplasia or early adenocarcinoma during surveillance endoscopy [15]. Important issues are the use of high-definition endoscopes, chromoendoscopy with acetic acid $[16,17]$ and/or virtual chromoendoscopy $[18,19]$, a sufficient inspection time (at least one minute per $\mathrm{cm}$ of segment length), and the application of a biopsy protocol with targeted biopsies from any suspicious lesion and four quadrant biopsies every 1-2 cm Barrett's length ("Seattle protocol") [9]. Several classification systems for the detection and evaluation of high-grade dysplasia 
and early adenocarcinoma in Barrett's esophagus have been proposed. The Barrett's International NBI Group (BING) classification [18] and the Japanese classification [19] both rely on surface and/or vessel irregularities identified with virtual narrow band imaging chromoendoscopy and show good sensitivity $(80-87 \%)$ and specificity $(88-97 \%)$ for the detection of dysplasia. The more recent proposed classification relies on surface irregularities and the loss of whitening of the mucosa after the application of acetic acid [16]. Using these descriptive criteria, a high sensitivity and a high negative predictive power for the presence or absence of Barrett's neoplasia could be demonstrated not only for expert, but also for non-expert endoscopists (Table 1; Figure $1 \mathrm{a}-\mathrm{d}$ ).
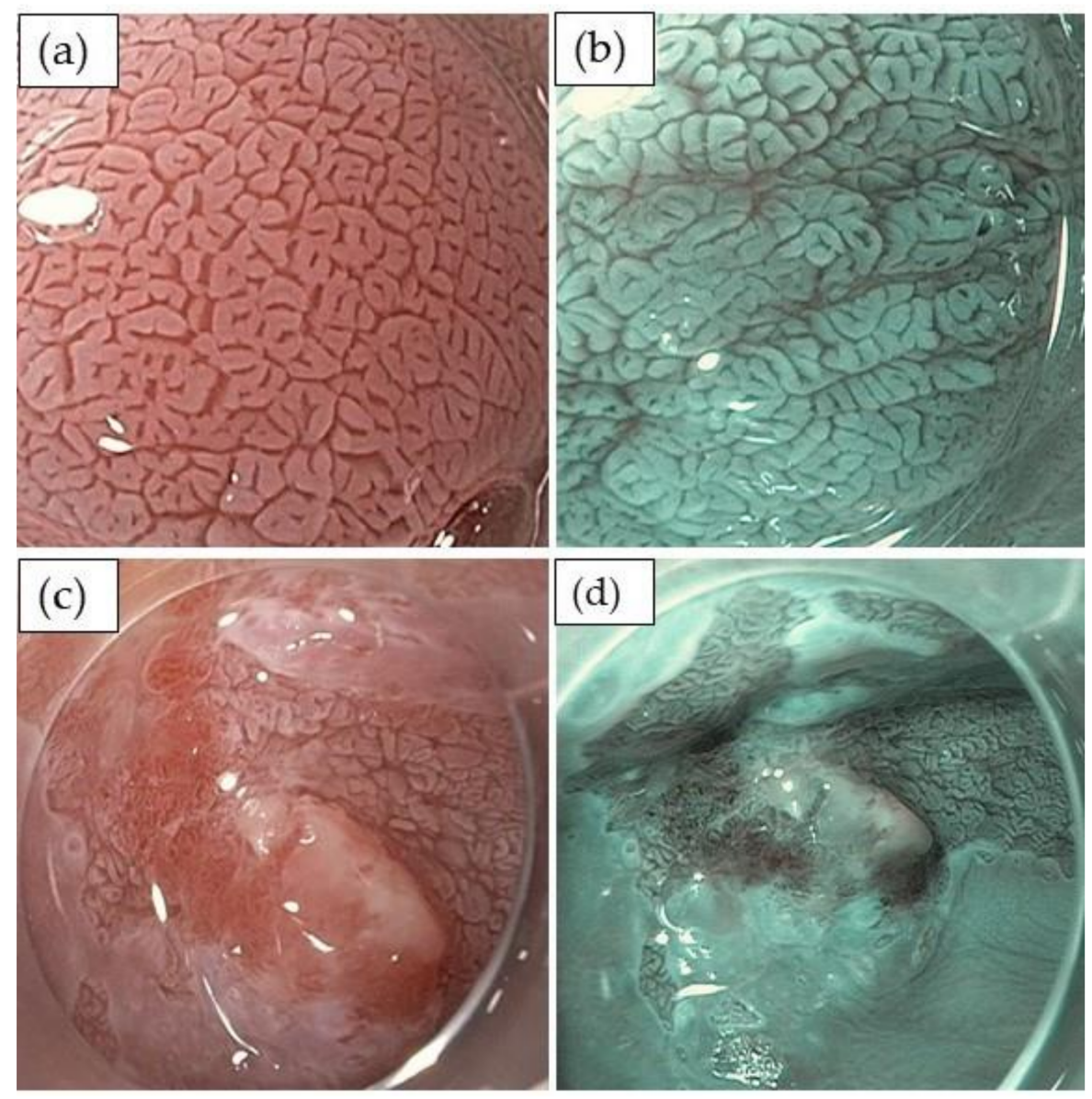

Figure 1. Endoscopic evaluation of Barrett's esophagus and dysplasia with chromoendoscopy using 1.5\% acetic acid. Top: non-dysplastic Barrett's with a regular surface structure: (a) white light imaging, (b) narrow band imaging. Bottom: Barrett's adenocarcinoma with the irregular surface structure and loss of acetowhitening: (c) white light imaging, (d) narrow band imaging.

Acetic acid staining can also be helpful to evaluate the extent of Barrett's cancer underneath the squamous epithelium [20]. In contrast to endoscopic image analysis (in particular with magnifying endoscopy), endoscopic ultrasound is less accurate in the prediction of infiltration depth [21]. However, endoscopic ultrasound is the most reliable method to detect possible lymph node metastasis and thus can be helpful in selected cases [22]. The additional acquisition of cytology with a specifically designed brush may increase the dysplasia detection rate and is included in the recommendations of the American Society for Gastrointestinal Endoscopy (ASGE) [9,23]. In the near future, artificial intelligence systems will become available to support the detection of dysplasia and early adenocarcinoma [24-26]. 
Table 1. Classification systems for Barrett's associated neoplasia $[16,18,19,27]$.

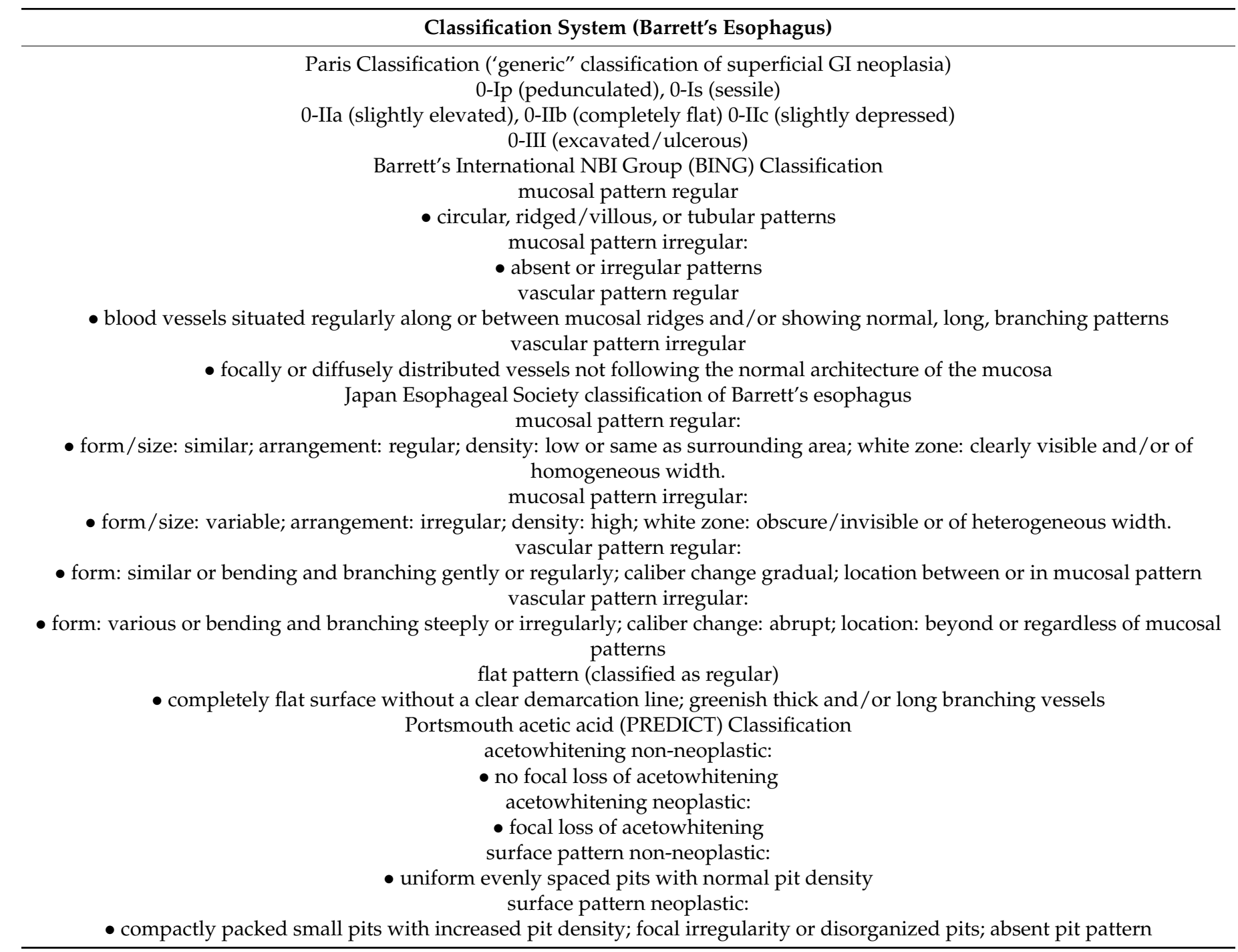

\subsection{Endoscopic Treatment of Dysplasia and Early Adenocarcinoma}

Pioneering work from Germany has established the concept of endoscopic mucosal resection (EMR) for high-grade dysplasia and mucosal esophageal adenocarcinoma [28]. This study included endoscopic resections for 1000 consecutive patients with T1a Barrett's mucosal adenocarcinoma. During a follow up period of almost five years, the complete response rate was $96.3 \%$. Surgery was necessary in $3.7 \%$ of the patients; metachronous neoplasia was detected in $14.5 \%$ and could be re-treated endoscopically in $81.4 \%$, yielding a long-term complete remission rate of $93.8 \%$. The same group also reported a series of 61 patients with endoscopic resection of low-risk T1b Barrett's cancer: $90 \%$ of those with lesions $\leq 2 \mathrm{~cm}$ were in remission during a follow up of approximately four years; one patient developed a lymph node metastasis; and there was no tumor-related mortality [29]. Therefore, EMR is the preferred resection technique in Western countries [30] (Figure 2a-d). In contrast, endoscopic submucosal dissection (ESD) is the recommended method in the Japanese guidelines [21]. In fact, ESD is more appropriate for larger lesions, in particular Paris Type 0-Is, and is recommended for suspicious lesions for which en bloc resection is not possible using endoscopic mucosal resection [8,31]. Moreover, ESD compares favorably to EMR with higher en bloc ( $96 \%$ vs. $50 \%$ ) and R0 resection rates $(82 \%$ vs. $40 \%)$ with less recurrences ( $2.5 \%$ vs. $12.4 \%$ ) [21]. Complication rates of endoscopic resection are low for both techniques [21,32]. They include perforation, bleeding, and, after resection of 
$>70-80 \%$ of the circumference, also strictures. In cases of early adenocarcinoma, the criteria for curative resection are (i) complete (R0) resection without involvement of lateral and vertical margins, (ii) no invasion of lymphatic or blood vessels, and (iii) tumor grading G1/2. Infiltration depth into the submucosal layer of $<500 \mu \mathrm{m}$ is acceptable, in particular for patients with high perioperative risk [33]. While involved vertical margins are usually an indication for additional surgery, endoscopic controls and secondary resection are recommended in cases of positive lateral margins (Table 2).
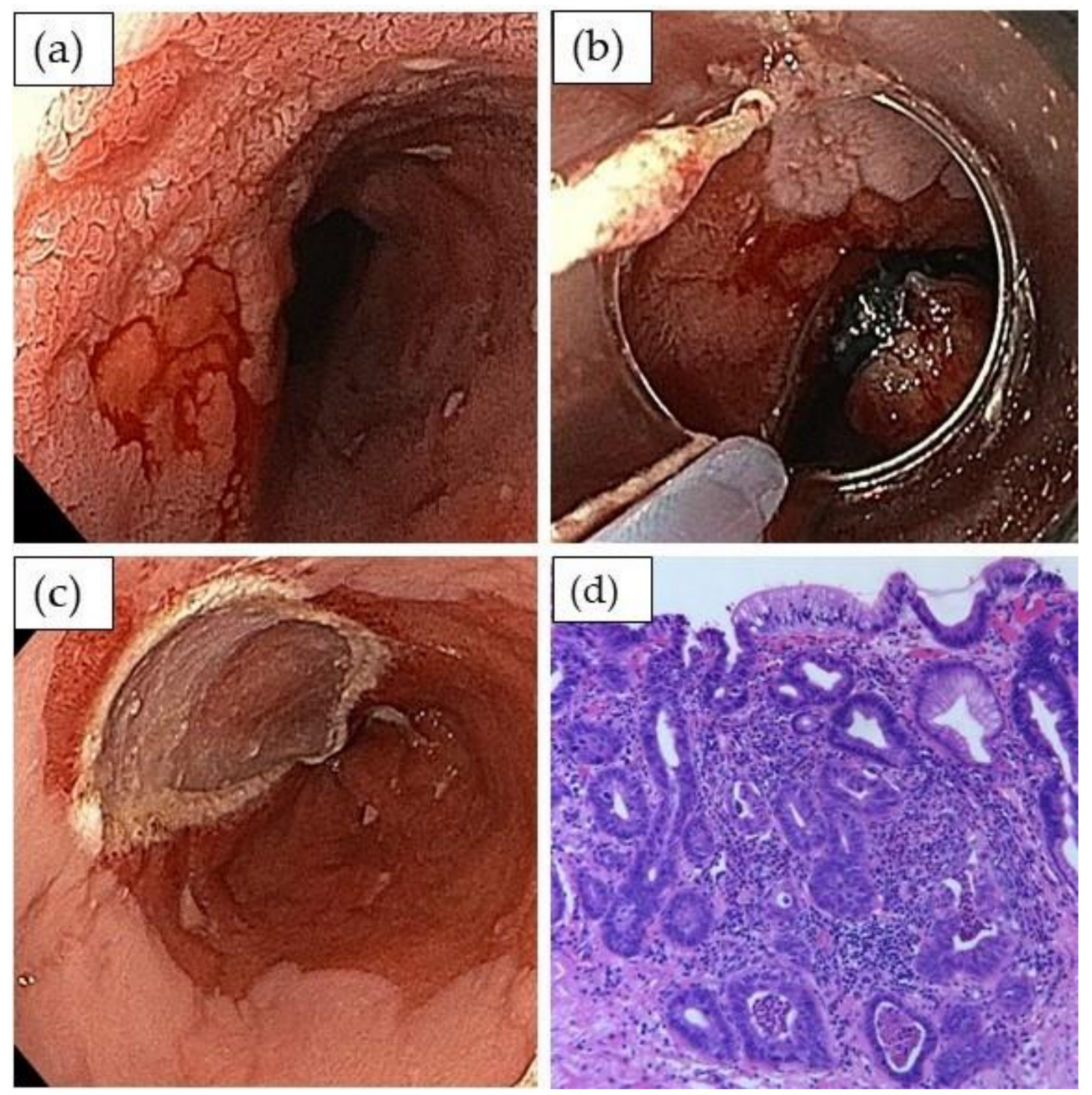

Figure 2. Endoscopic mucosal resection (EMR) of early adenocarcinoma with the suck and cut technique. (a) Long segment Barrett's cancer with suspicious lesion to the left (white light imaging, acetic acid 1.5\%); (b) lesion is band ligated and resected with the snare placed underneath the rubber band; (c) resection bed without any associated bleeding; (d) histopathology shows well differentiated intramucosal adenocarcinoma without infiltration of lymphatic or blood vessels pT1a m3, ly(-), v(-) G2 (H\&E stain, $\times 400)$.

Table 2. Criteria for curative endoscopic resection of Barrett's cancer [30].

\begin{tabular}{c}
\hline Criteria for Curative Endoscopic Resection \\
\hline - Resection en bloc/R0 (vertical margin) \\
$\bullet$ Grading G1/G21 \\
$\bullet$ No infiltration of lymphatic/blood vessels \\
$\bullet$ Submucosal infiltration depth $\leq 500 \mu \mathrm{m}$ \\
\hline
\end{tabular}




\subsection{Additional Treatment and Follow-Up}

The development of metachronous neoplasia from residual Barrett's metaplasia after endoscopic resection of high-grade dysplasia/early adenocarcinoma has been reported in up to $37 \%$ of cases during a two year follow up [34]. Thus, current guidelines recommend complete ablation of the remaining Barrett's epithelium [31,33,35] (Figure 3). This is usually performed by radiofrequency ablation starting from ca. $5-10 \mathrm{~mm}$ above the squamocolumnar junction to 5-10 mm distal to the "neo Z-line". Tissue ablation can also be achieved by argon plasma coagulation, cryo-ablation, or photodynamic therapy $[35,36]$. A major complication of ablation therapy is a stricture rate of approximately $5 \%$ [33]. A recently published study on 807 patients reported a $4.5 \%$ neoplasia recurrence rate after mucosal ablation, which peaked within the first 18 months [37].

\section{Treatment of Barrett's high grade dysplasia / cancer}

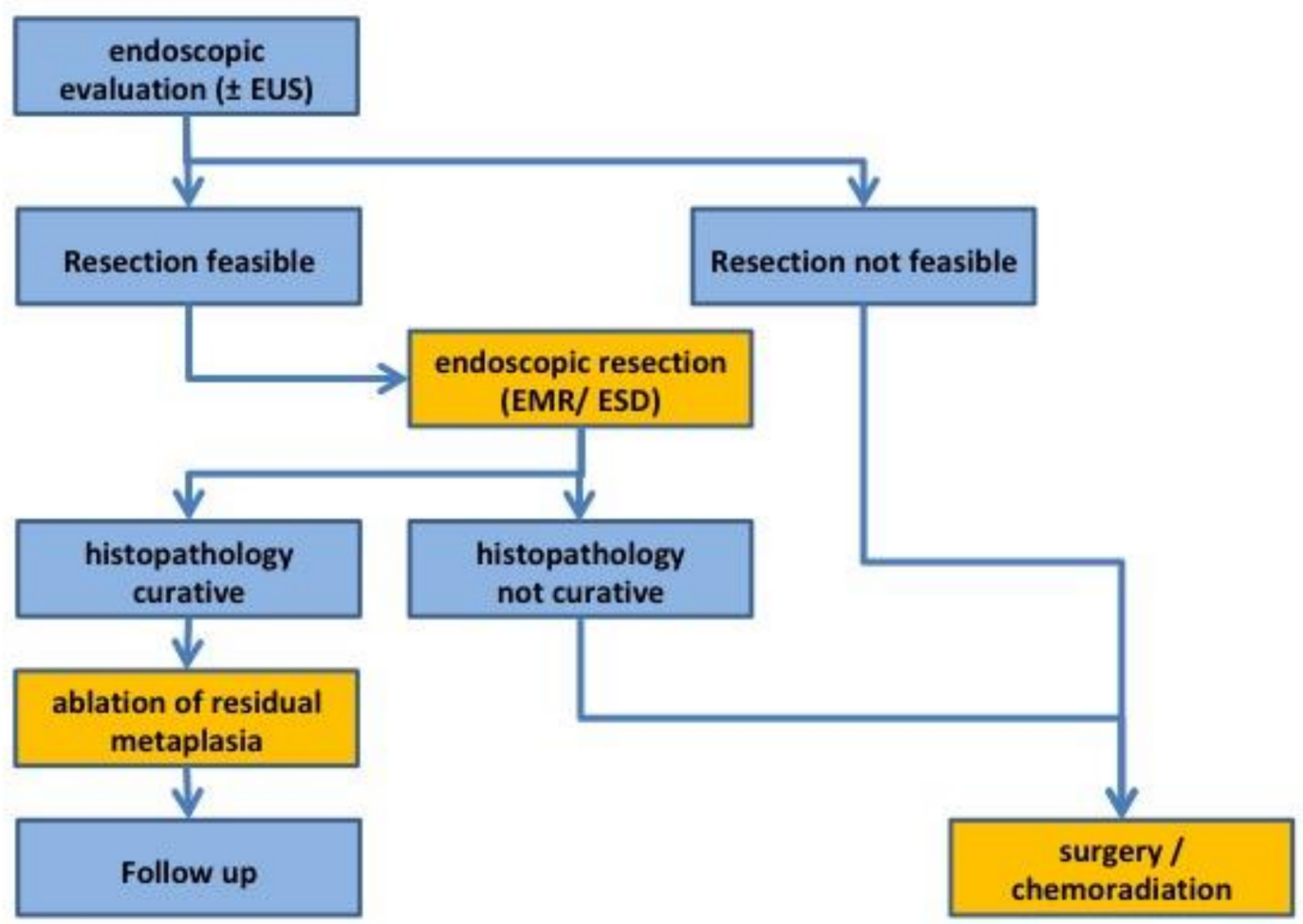

Figure 3. Proposed treatment algorithm according to current guidelines [30]. Evaluation may include endoscopic ultrasound to assess possible lymph node metastasis. Criteria for curative resection are listed in Table 2. EUS, endoscopic ultrasound; EMR, endoscopic mucosal resection; ESD, endoscopic submucosal dissection.

Mucosal ablation can also be considered for confirmed non-visible low-grade dysplasia [38] or high-grade dysplasia and early cancer. However, a recent meta-analysis suggests that visible high-grade dysplasia or early cancer is best treated by a combination of endoscopic resection and additive ablation rather than using just radiofrequency ablation [39]. An endoscopic follow up after 3, 6, and 12 months and yearly thereafter has been suggested after endoscopic resection and/or mucosal ablation [33]. The approach to recurrent or metachronous neoplasia is similar to initial therapy [30] and the vast majority of these lesions can be re-treated endoscopically [28]. 


\section{Squamous Cell High-Grade Dysplasia and Early Cancer \\ 3.1. Screening for Squamous Cell Dysplasia or Early Cancer}

As for Barrett's esophagus, there is no established population-based screening for esophageal squamous cell cancer. However, endoscopic screening should be considered in the presence of risk factors, e.g., after diagnosis of head and neck cancer, in cases of long standing achalasia, or for persons with heavy smoking and drinking [40]. Vice versa, there is an increased risk for head and neck cancer in patients treated for superficial esophageal squamous cell cancer [41]. Screening for esophageal cancer is probably best performed by chromoendoscopy, after staining with a low concentration of Lugol's solution or by virtual chromoendoscopy such as narrow band imaging [42,43]. A disadvantage of dye chromoendoscopy with Lugol's solution, in particular at higher concentrations, is the induction of a painful inflammatory reaction. This inflammatory reaction interferes with the delineation of the borders of the lesion for up to several weeks. Thus, dye staining is usually done immediately before the beginning of endoscopic resection.

\subsection{Detection and Evaluation of Squamous Cell Dysplasia or Early Cancer}

Endoscopic evaluation of a detected lesion to predict the infiltration depth is critical since lymph node metastasis in squamous cell cancer is mainly associated with invasion depth [19]. The simplified classification of the Japan Esophageal Society uses vessel irregularities (loop formation, loss of loop formation, dilated and tortuous vessel) observed with regular or magnification endoscopy to predict infiltration depth [44] (Table 3; Figure 4a-d). The diagnostic accuracy is over $90 \%$ for B1 and B3 vessel patterns in predicting either superficial infiltration depth, i.e., epithelial (pT1a-EP) or lamina propria (pT1a-LPM) infiltration, or for the prediction of deep submucosal infiltration (pT1b-pSM2). In contrast, the vessel pattern B2 has an accuracy of only $55.7 \%$ for predicting an infiltration depth to the muscularis mucosae (pT1b-MM) or to the upper submucosal layer (pT1b-SM1). Endoscopic ultrasound has a relatively lower diagnostic accuracy for the evaluation of squamous cell cancer infiltration depth, but has its value as the most accurate diagnostic tool to assess possible lymph node metastasis [21,22].

Table 3. Japanese classification for early squamous cell cancer [44].

\begin{tabular}{c}
\hline Japan Esophageal Society (JES) Classification of Early Squamous Cell Cancer to Assess \\
Tumor Infiltration Depth \\
Vascular pattern regular \\
Type A vessels \\
Type B vessels \\
Abnormal microvessels (severe irregularity/highly dilated abnormal vessels) \\
$\bullet$ Type B1 with a loop-like formation \\
$\bullet$ Type B2 without a loop-like formation \\
- Type B3 highly dilated vessels, the calibers of which appear to be more than three times that of \\
usual B2 vessels
\end{tabular}

\subsection{Endoscopic Treatment}

The recommended technique for endoscopic en bloc resection of early esophageal squamous cell cancer is ESD. Compared to EMR, ESD achieves higher en bloc ( $96 \%$ vs. $50 \%$ ) and R0 resection rates ( $82 \%$ vs. $40 \%$ ) and lower recurrence rates ( $2.5 \%$ vs. $12.4 \%$ ) [21]. To facilitate the delineation of the lateral tumor extension, chromoendoscopy with Lugol's solution is performed immediately before the procedure. The use of a traction device, e.g., the clip line technique [45], is useful to facilitate the resection in the narrow lumen of the esophagus. According to the recent Japanese guideline, endoscopic resection should be undertaken for all lesions with the B1 vessel pattern (predicted infiltration depth T1aEP/LPM), unless the lesion is completely circumferential and has an axial extension of more than $5 \mathrm{~cm}$. In addition, ESD should also be attempted for lesions with B2 vessel patterns (predicted infiltration depth T1a-MM/T1b-SM1) unless completely circumferential since 
there is a high probability that histopathology may reveal a more superficial infiltration depth and might thus be a curative resection (Figure $5 \mathrm{a}-\mathrm{d}$ ). Curability is then evaluated by final histopathology: resection is considered curative for R0 resected superficial tumors without infiltration of lymphatic or blood vessels, i.e., pT1a-EP/LPM ly (-), v (-) (Table 4). In cases of vessel infiltration or infiltration of the submucosal layer, additional treatment (either surgery or chemo-radiotherapy) is recommended [21]. Data from observational studies comparing endoscopic resection with surgery for cT1a cancers demonstrate lower complication rates and associated health care costs with similar clinical outcomes for endoscopic treatment $[21,46]$.
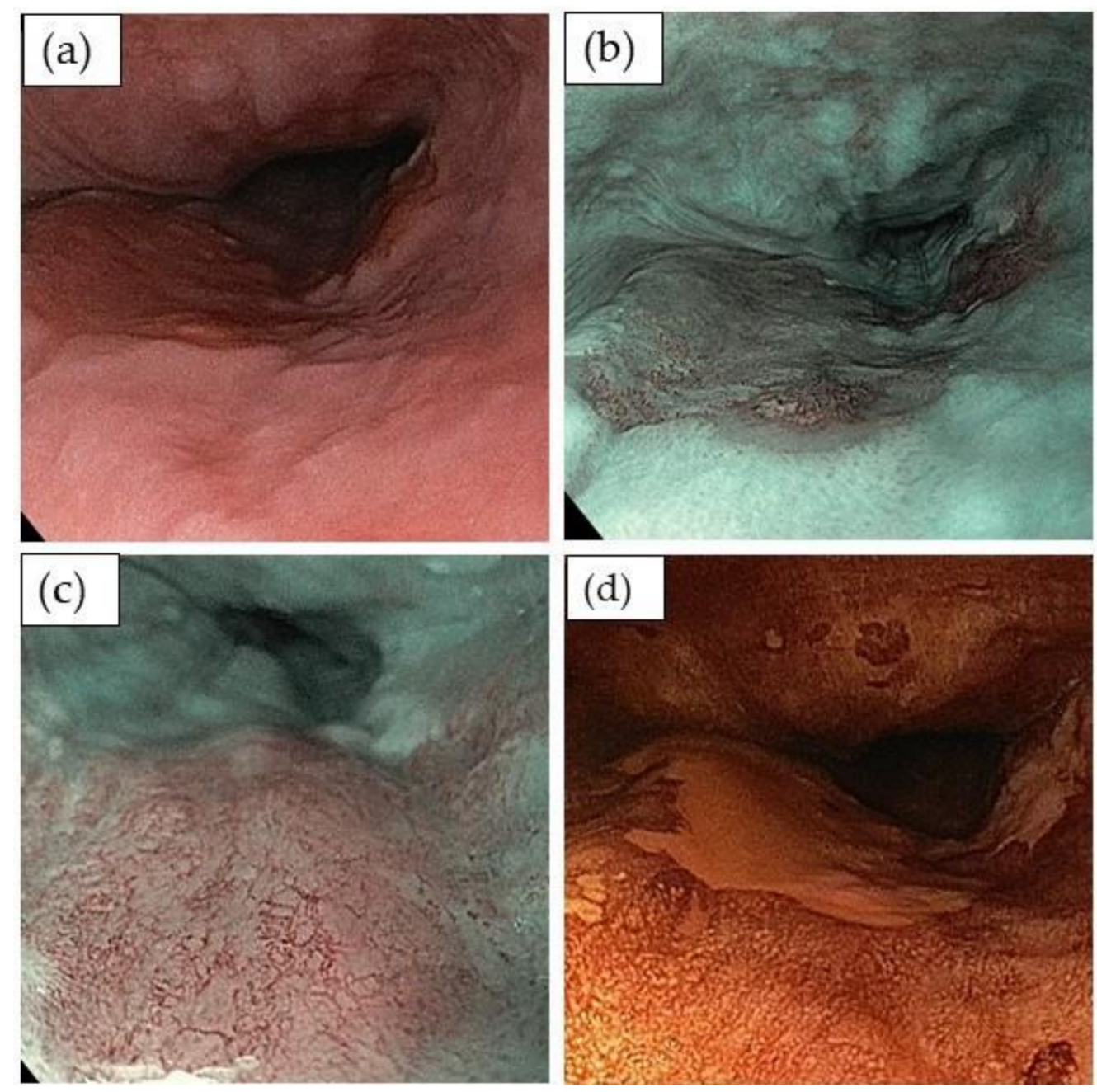

Figure 4. Endoscopic evaluation of early squamous cell cancer by endoscopic submucosal dissection: (a) irregular surface structure in the mid esophagus (white light imaging); (b) virtual chromoendoscopy of this area shows a brownish are with better definition of the borders (narrow band imaging); (c) close view of the lesion showing vessel irregularities (type B2 vessels); (d) chromoendoscopy with $0.5 \%$ Lugol's solution nicely delineates the borders of the lesions and is ideally used immediately before starting an endoscopic resection. 

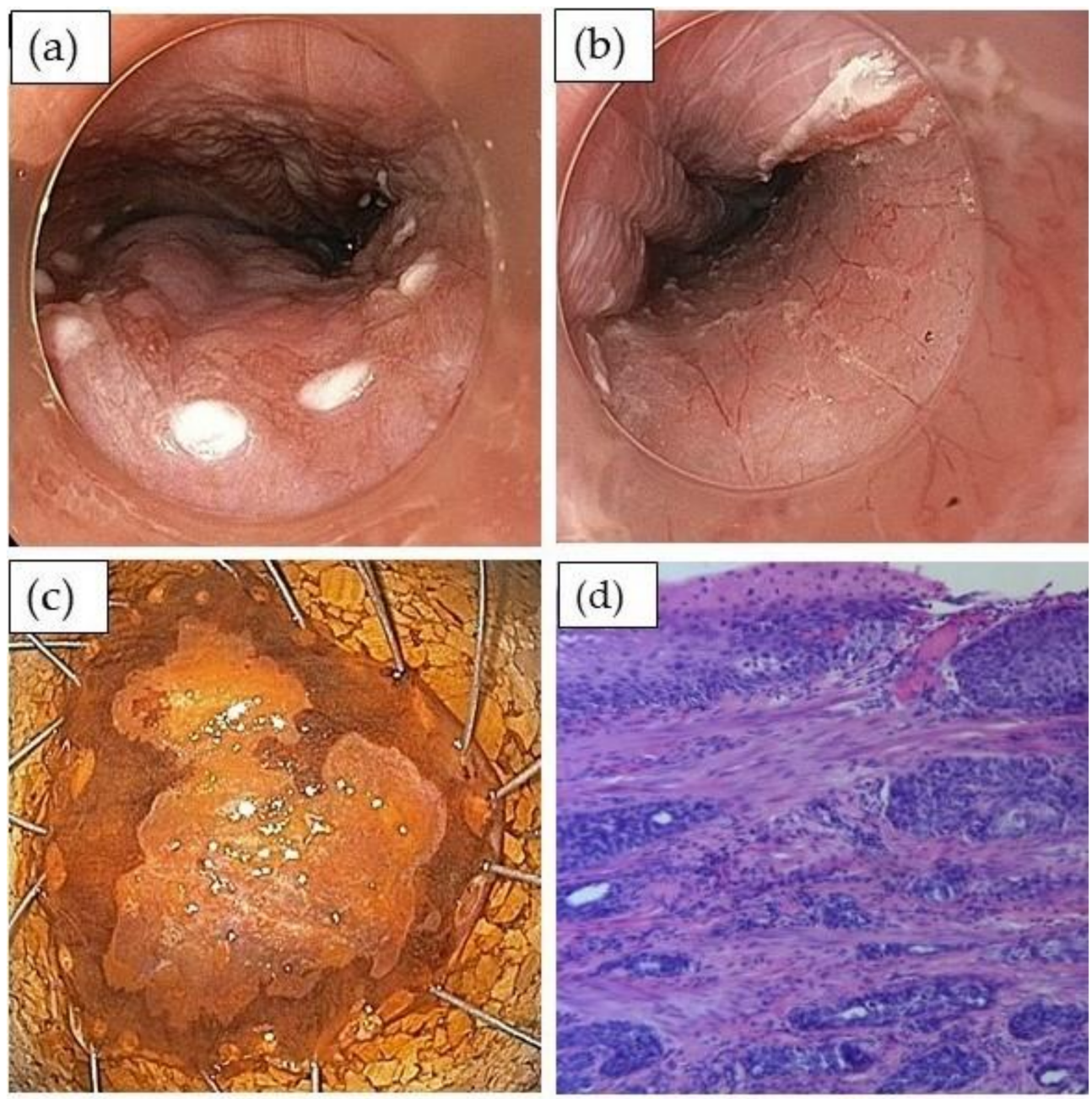

Figure 5. Endoscopic resection of early squamous cell cancer by endoscopic submucosal dissection: (a) after chromoendoscopy with Lugol's solution, the borders of the lesion are marked with coagulation points; (b) resection bed without any associated bleeding; (c) specimen on corkboard (after repeated staining with Lugol's solution); (d) histopathology shows poorly differentiated pT1b squamous cell cancer $(H \& E$ stain, $\times 400)$.

Table 4. Criteria for curative endoscopic resection of early squamous cell cancer.

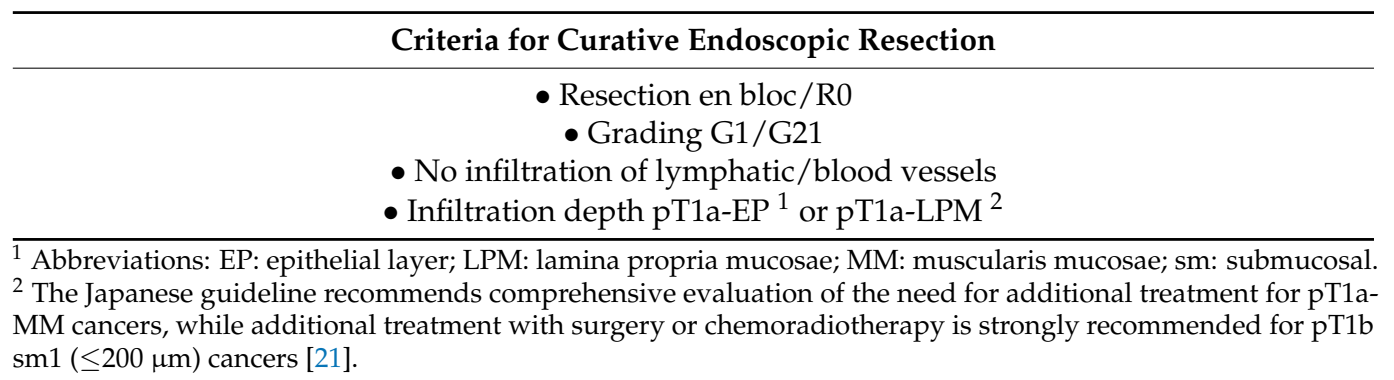

\subsection{Additional Treatment and Follow-Up}

Additional surgery or definitive chemo-radiotherapy is recommended after non curative resection [21] (Figure 6). Recently, excellent data have been published for adjuvant chemo-radiotherapy after complete endoscopic resection of T1b (SM1-2) cancers [47]. In this prospective observational study, 176 patients were treated with endoscopic resection of early esophageal squamous cell cancer. After histopathology, eighty-seven patients had either pT1a tumors with lympho-vascular invasion or pT1b tumors. These patients were 
treated by adjuvant chemo-radiotherapy (41.4 Gy) and had an overall three year survival of $90.7 \%$. This outcome is comparable to published outcome data for surgery, and the rate of local recurrences is less than after primary chemo-radiotherapy [47]. The annual risk for metachronous esophageal is between 2.2 and $9.0 \%$, and most recurrences can be treated endoscopically [19]. Thus, endoscopic follow-up and surveillance are recommended to be done in at least yearly intervals after curative local treatment. In addition, screening for synchronous head and neck, as well as lung cancers is also recommended [21].

\section{Treatment of early squamous cell cancer}

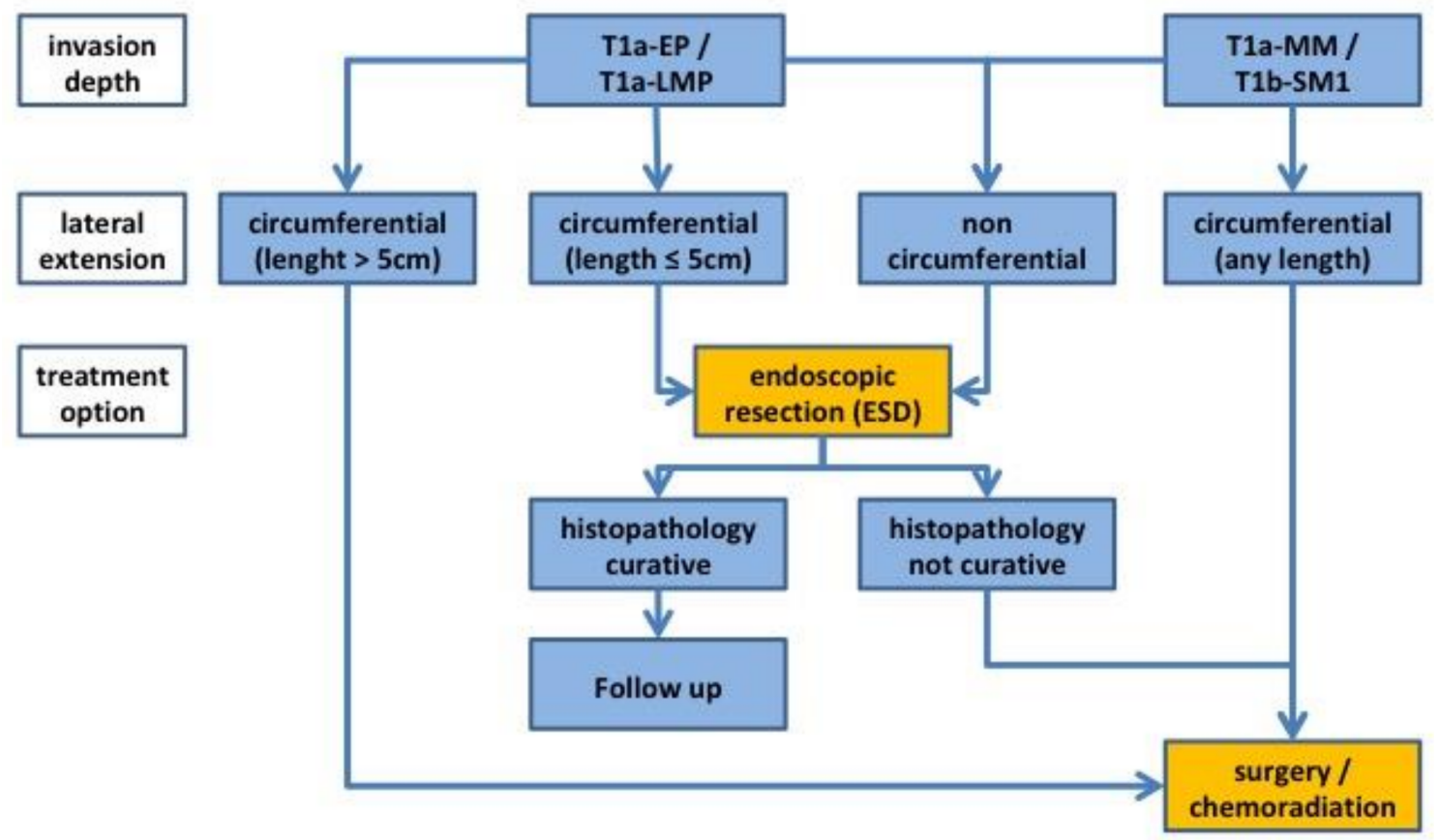

Figure 6. Proposed treatment algorithm of early esophageal squamous cell cancer according to current Japanese guidelines [21]. Evaluation should include endoscopic ultrasound to assess possible lymph node metastasis in selected cases. Invasion depth is diagnosed according to the Japan Esophageal Society (JES) classification (Table 3). Lateral extension is usually visualized by chromoendoscopy with Lugol's solution. Criteria for curative resection are listed in Table 4. ESD, endoscopic submucosal dissection; EP, epithelial layer; LMP, lamina propria mucosae; MM, muscularis mucosae.

\section{Conclusions}

Endoscopic detection and treatment of high-grade dysplasia and early esophageal cancer are established concepts for neoplasia with low or absent lymph node metastasis risk. Areas of research are (i) indications for endoscopic screening, (ii) optimizing of screening efficiency, and (iii) extending the concept of organ-preserving therapy by adjuvant treatment strategies. Screening may become more efficient with non-endoscopic pretesting, with promising data from cytosponge procedures or the use of an artificial intelligencebased breath test. The optimization of the neoplasia detection rate is important. Here, the widespread availability of high-definition endoscopy with virtual and/or dye-based chromoendoscopy is helpful. Moreover, additional support will soon be available from artificial intelligence image analysis systems. Finally, adjuvant treatment, e.g., chemoradiotherapy may help to extend the curative ability of minimally invasive endoscopic therapy of early esophageal cancer in cases of high lymph node metastasis risk. 
Author Contributions: F.L.D. and I.S. worked out the concept of the paper and wrote the draft. T.O. and R.H. provided additional input and contributed to the figures. All authors read and agreed to the published version of the manuscript.

Funding: This research received no external funding.

Data Availability Statement: No new data were created or analyzed in this study. Data sharing is not applicable to this article.

Conflicts of Interest: The authors declare no conflict of interest.

\section{References}

1. Arnold, M.; Abnet, C.C.; Neale, R.E.; Vignat, J.; Giovannucci, E.L.; McGlynn, K.A.; Bray, F. Global Burden of 5 Major Types of Gastrointestinal Cancer. Gastroenterology 2020, 159, 335-349. [CrossRef]

2. Malhotra, G.K.; Yanala, U.; Ravipati, A.; Follet, M.; Vijayakumar, M.; Are, C. Global trends in esophageal cancer. J. Surg. Oncol. 2017, 115, 564-579. [CrossRef] [PubMed]

3. Que, J.; Garman, K.S.; Souza, R.F.; Spechler, S.J. Pathogenesis and cells of origin of Barrett's esophagus. Gastroenterology 2019, 157, 349-364. [CrossRef]

4. $\quad$ Desai, M.; Lieberman, D.A.; Kennedy, K.F.; Hamade, N.; Thota, P.; Parasa, S.; Gorrepati, V.S.; Bansal, A.; Gupta, N.; Gaddam, S.; et al. Increasing prevalence of high-grade dysplasia and adenocarcinoma on index endoscopy in Barrett's esophagus over the past 2 decades: Data from a multicenter U.S. consortium. Gastrointest. Endosc. 2019, 89, 257-263. [CrossRef]

5. Peters, Y.; Al-Kaabi, A.; Shaheen, N.J.; Chak, A.; Blum, A.; Souza, R.F.; Di Pietro, M.; Iyer, P.G.; Pech, O.; Fitzgerald, R.C.; et al. Barrett oesophagus. Nat. Rev. Dis. Prim. 2019, 5, 35. [CrossRef]

6. Spechler, S.J.; Sharma, P.; Souza, R.F.; Inadomi, J.M.; Shaheen, N.J. American Gastroenterological Association medical position statement on the management of Barrett's esophagus. Gastroenterology 2011, 140, 1084-1091. [CrossRef]

7. Fitzgerald, R.C.; Di Pietro, M.; Ragunath, K.; Ang, Y.; Kang, J.Y.; Watson, P.; De Caestecker, J. British Society of Gastroenterology guidelines on the diagnosis and management of Barrett's oesophagus. Gut 2014, 63, 7-42. [CrossRef] [PubMed]

8. Weusten, B.; Bisschops, R.; Coron, E.; Dinis-Ribeiro, M.; Dumonceau, J.-M.; Esteban, J.-M.; Hassan, C.; Pech, O.; Repici, A.; Bergman, J.; et al. Endoscopic management of Barrett's esophagus: European Society of Gastrointestinal Endoscopy (ESGE) Position Statement. Eur. Soc. Gastrointest. Endosc. Position Statement 2017, 49, 191-198. [CrossRef]

9. Qumseya, B.; Sultan, S.; Bain, P.; Jamil, L.; Jacobson, B.; Anandasabapathy, S.; Agrawal, D.; Buxbaum, J.L.; Fishman, D.S.; Gurudu, S.R.; et al. ASGE guideline on screening and surveillance of Barrett's esophagus. Gastrointest. Endosc. 2019, 90, 335-359. [CrossRef] [PubMed]

10. Nguyen, T.H.; Thrift, A.P.; Rugge, M.; El-Serag, H.B. Prevalence of Barrett's esophagus and performance of societal screening guidelines in an unreferred primary care population of U.S. veterans. Gastrointest. Endosc. e1. [CrossRef] [PubMed]

11. Fitzgerald, R.C.; di Pietro, M.; O’Donovan, M.; Maroni, R.; Muldrew, B.; Debiram-Beecham, I.; Gaw, M. Cytosponge-trefoil factor 3 versus usual care to identify Barrett's oesophagus in a primary care setting: A multicentre, pragmatic, randomised controlled trial. Lancet 2020, 396, 333-344. [CrossRef]

12. Peters, Y.; Schrauwen, R.W.M.; Tan, A.C.; Bogers, S.K.; De Jong, B.; Siersema, P.D. Detection of Barrett's oesophagus through exhaled breath using an electronic nose device. Gut 2020, 69, 1169-1172. [CrossRef]

13. Rodríguez de Santiago, E.; Hernanz, N.; Marcos-Prieto, H.M.; De-Jorge-Turrión M, Á.; Barreiro-Alonso, E.; Rodríguez-Escaja, C.; Albillos, A. Rate of missed oesophageal cancer at routine endoscopy and survival outcomes: A multicentric cohort study. United Eur. Gastroenterol. J. 2019, 7, 189-198.

14. Parasa, S.; Desai, M.; Vittal, A.; Chandrasekar, V.T.; Pervez, A.; Kennedy, K.F.; Gupta, N.; Shaheen, N.J.; Sharma, P. Estimating neoplasia detection rate (NDR) in patients with Barrett's oesophagus based on index endoscopy: A systematic review and meta-analysis. Gut 2019, 68, 2122-2128. [CrossRef] [PubMed]

15. Bergman, J.; De Groof, A.J.; Pech, O.; Ragunath, K.; Armstrong, D.; Mostafavi, N.; Lundell, L.; Dent, J.; Vieth, M.; Tytgat, G.; et al. An Interactive Web-Based Educational Tool Improves Detection and Delineation of Barrett's Esophagus-Related Neoplasia. Gastroenterology 2019, 156, 1299-1308. [CrossRef]

16. Kandiah, K.; Chedgy, F.J.Q.; Subramaniam, S.; Longcroft-Wheaton, G.; Bassett, P.; Repici, A.; Sharma, P.; Pech, O.; Bhandari, P. International development and validation of a classification system for the identification of Barrett's neoplasia using acetic acid chromoendoscopy: The Portsmouth acetic acid classification (PREDICT). Gut 2017, 67, 2085-2091. [CrossRef] [PubMed]

17. Chedgy, F.J.; Subramaniam, S.; Kandiah, K.; Thayalasekaran, S.; Bhandari, P. Acetic acid chromoendoscopy: Improving neoplasia detection in Barrett's esophagus. World J. Gastroenterol. 2016, 22, 5753. [CrossRef]

18. Sharma, P.; Bergman, J.J.G.H.M.; Goda, K.; Kato, M.; Messmann, H.; Alsop, B.R.; Gupta, N.; Vennalaganti, P.; Hall, M.; A Konda, V.J.; et al. Development and Validation of a Classification System to Identify High-Grade Dysplasia and Esophageal Adenocarcinoma in Barrett's Esophagus Using Narrow-Band Imaging. Gastroenterol. 2016, 150, 591-598. [CrossRef] [PubMed]

19. Ishihara, R.; Goda, K.; Oyama, T. Endoscopic diagnosis and treatment of esophageal adenocarcinoma: Introduction of Japan Esophageal Society classification of Barrett's esophagus. J. Gastroenterol. 2018, 54, 1-9. [CrossRef] 
20. Iwaya, Y.; Rowsell, C.; Gupta, V.; Marcon, N. Buried Barrett's Adenocarcinoma Clearly Demonstrated with Acetic Acid Chromoendoscopy. Am. J. Gastroenterol. 2018, 113, 1580. [CrossRef]

21. Ishihara, R.; Arima, M.; Iizuka, T.; Oyama, T.; Katada, C.; Kato, M.; Goda, K.; Goto, O.; Tanaka, K.; Yano, T.; et al. Endoscopic submucosal dissection/endoscopic mucosal resection guidelines for esophageal cancer. Dig. Endosc. 2020, 32, 452-493. [CrossRef]

22. Ahmed, O.; A Ajani, J.; Lee, J.H. Endoscopic management of esophageal cancer. World J. Gastrointest. Oncol. 2019, 11, 830-841. [CrossRef]

23. Raphael, K.L.; Stewart, M.; Sejpal, D.V.; Cheung, M.; Whitson, M.J.; Han, D.; Trindade, A.J. Adjunctive yield of wide-area transepithelial sampling for dysplasia detection after advanced imaging and random biopsies in Barrett's esophagus. Clin. Transl. Gastroenterol. 2019, 10, 12. [CrossRef] [PubMed]

24. de Groof, A.J.; Struyvenberg, M.R.; Van Der Putten, J.; Van Der Sommen, F.; Fockens, K.N.; Curvers, W.L.; Zinger, S.; Pouw, R.E.; Coron, E.; Baldaque-Silva, F.; et al. Deep-Learning System Detects Neoplasia in Patients With Barrett's Esophagus With Higher Accuracy Than Endoscopists in a Multistep Training and Validation Study With Benchmarking. Gastroenterologgy 2020, 158, 915-929. [CrossRef] [PubMed]

25. Ebigbo, A.; Mendel, R.; Probst, A.; Manzeneder, J.A.D.S.; Papa, J.P.; Palm, C.; Messmann, H. Computer-aided diagnosis using deep learning in the evaluation of early oesophageal adenocarcinoma. Gut 2013, 68, 1143. [CrossRef]

26. Hashimoto, R.; Requa, J.; Dao, T.; Ninh, A.; Tran, E.; Mai, D.; Lugo, M.; Chehade, N.E.-H.; Chang, K.J.; Karnes, W.E.; et al. Artificial intelligence using convolutional neural networks for real-time detection of early esophageal neoplasia in Barrett's esophagus (with video). Gastrointest. Endosc. 2020, 91, 1264-1271. [CrossRef]

27. Endoscopic Classification Review Group. Update on the paris classification of superficial neoplastic lesions in the digestive tract. Endoscopy 2005, 37, 570-578. [CrossRef] [PubMed]

28. Pech, O.; May, A.; Manner, H.; Behrens, A.; Pohl, J.; Weferling, M.; Hartmann, U.; Manner, N.; Huijsmans, J.; Gossner, L.; et al. Long-term Efficacy and Safety of Endoscopic Resection for Patients With Mucosal Adenocarcinoma of the Esophagus. Gastroenterol. 2014, 146, 652-660. [CrossRef]

29. Manner, H.; Pech, O.; Heldmann, Y.; May, A.; Pohl, J.; Behrens, A.; Gossner, L.; Stolte, M.; Vieth, M.; Ell, C. Efficacy, Safety, and Long-term Results of Endoscopic Treatment for Early Stage Adenocarcinoma of the Esophagus with Low-risk sm1 Invasion. Clin. Gastroenterol. Hepatol. 2013, 11, 630-635. [CrossRef] [PubMed]

30. Sharma, P.; Shaheen, N.J.; Katzka, D.; Bergman, J.J. AGA clinical practice update on endoscopic treatment of Barrett's esophagus with dysplasia and/or early cancer: Expert review. Gastroenterology 2020, 158, 760-769.

31. Noordzij, I.C.; Curvers, W.L.; Schoon, E.J. Endoscopic resection for early esophageal carcinoma. J. Thorac. Dis. 2019, 11, S713-S722. [CrossRef] [PubMed]

32. Pimentel-Nunes, P.; Dinis-Ribeiro, M.; Ponchon, T.; Repici, A.; Vieth, M.; De Ceglie, A.; Amato, A.; Berr, F.; Bhandari, P.; Bialek, A.; et al. Endoscopic submucosal dissection: European Society of Gastrointestinal Endoscopy (ESGE) Guideline. Endoscopy 2015, 47, 829-854. [CrossRef] [PubMed]

33. Sharma, P.; Shaheen, N.J.; Katzka, D.; Bergman, J. Clinical Practice Update: Endoscopic Treatment of Barrett's Esophagus With Dysplasia and/or Early Cancer. Gastroenterology 2019. [PubMed]

34. Manner, H.; Rabenstein, T.; Pech, O.; Braun, K.; May, M.A.; Pohl, J.; Behrens, A.; Vieth, M.; Ell, C. Ablation of residual Barrett's epithelium after endoscopic resection: A randomized long-term follow-up study of argon plasma coagulation vs. surveillance (APE study). Endoscopy 2013, 12. [CrossRef] [PubMed]

35. Lal, P.; Thota, P.N. Cryotherapy in the management of premalignant and malignant conditions of the esophagus. World J. Gastroenterol. 2018, 24, 4862-4869. [CrossRef] [PubMed]

36. Hamade, N.; Desai, M.; Thoguluva Chandrasekar, V.; Chalhoub, J.; Patel, M.; Duvvuri, A.; Sharma, P. Efficacy of cryotherapy as first line therapy in patients with Barrett's neoplasia: A systematic review and pooled analysis. Dis. Esophagus 2019, 32, doz040. [CrossRef]

37. Wani, S.; Han, S.; Kushnir, V.; Early, D.; Mullady, D.; Hammad, H.; Brauer, B.; Thaker, A.; Simon, V.; Ezekwe, E.; et al. Recurrence Is Rare Following Complete Eradication of Intestinal Metaplasia in Patients With Barrett's Esophagus and Peaks at 18 Months. Clin. Gastroenterol. Hepatol. 2020. [CrossRef]

38. di Pietro, M.; Fitzgerald, R.C. Revised British Society of Gastroenterology recommendation on the diagnosis and management of Barrett's oesophagus with low-grade dysplasia. Gut 2018, 67, 392-393. [CrossRef]

39. de Matos, M.V.; da Ponte-Neto, A.M.; de Moura DT, H.; Maahs, E.D.; Chaves, D.M.; Baba, E.R.; de Moura EG, H. Treatment of highgrade dysplasia and intramucosal carcinoma using radiofrequency ablation or endoscopic mucosal resection+ radiofrequency ablation: Meta-analysis and systematic review. World J. Gastrointest. Endosc. 2019, 11, 239. [CrossRef] [PubMed]

40. van de Ven SE, M.; Bugter, O.; Hardillo, J.A.; Bruno, M.J.; Baatenburg de Jong, R.J.; Koch, A.D. Screening for head and neck second primary tumors in patients with esophageal squamous cell cancer: A systematic review and meta-analysis. United Eur. Gastroenterol. J. 2019, 7, 1304-1311.

41. Maekawa, A.; Ishihara, R.; Iwatsubo, T.; Nakagawa, K.; Ohmori, M.; Iwagami, H.; Matsuno, K.; Inoue, S.; Arao, M.; Nakahira, H.; et al. High incidence of head and neck cancers after endoscopic resection for esophageal cancer in younger patients. $J$. Gastroenterol. 2019, 55, 401-407. [CrossRef] [PubMed] 
42. Bugter, O.; van de Ven, S.E.; Hardillo, J.A.; Bruno, M.J.; Koch, A.D.; Baatenburg de Jong, R.J. Early detection of esophageal second primary tumors using Lugol chromoendoscopy in patients with head and neck cancer: A systematic review and meta-analysis. Head Neck 2019, 41, 1122-1130.

43. Su, H.-A.; Hsiao, S.-W.; Hsu, Y.-C.; Wang, L.-Y.; Yen, H.-H. Superiority of NBI endoscopy to PET/CT scan in detecting esophageal cancer among head and neck cancer patients: A retrospective cohort analysis. BMC Cancer 2020, 20, 1-9. [CrossRef]

44. Oyama, T.; Inoue, H.; Arima, M.; Momma, K.; Tomori, A.; Ishihara, R.; Hirasawa, D.; Takeuchi, M.; Goda, K. Prediction of the invasion depth of superficial squamous cell carcinoma based on microvessel morphology: Magnifying endoscopic classification of the Japan Esophageal Society. Esophagus 2017, 14, 105-112. [CrossRef] [PubMed]

45. Oyama, T. Counter Traction Makes Endoscopic Submucosal Dissection Easier. Clin. Endosc. 2012, 45, 375-378. [CrossRef] [PubMed]

46. Raman, V.; Jawitz, O.K.; Voigt, S.L.; Yang, C.-F.J.; Harpole, D.H.; D'Amico, T.A.; Hartwig, M.G. The effect of age on survival after endoscopic resection versus surgery for T1a esophageal cancer. J. Thorac. Cardiovasc. Surg. 2020, 160, 295-302. [CrossRef]

47. Minashi, K.; Nihei, K.; Mizusawa, J.; Takizawa, K.; Yano, T.; Ezoe, Y.; Muto, M. Efficacy of endoscopic resection and selective chemoradiotherapy for stage I esophageal squamous cell carcinoma. Gastroenterology 2019, 157, 382-390. [CrossRef] [PubMed] 